\title{
Premedication with nasal s-ketamine and midazolam provides good conditions for induction of anesthesia in preschool children
}

\author{
[La prémédication nasale avec s-kétamine et de midazolam fournit de bonnes \\ conditions d'induction de l'anesthésie chez de jeunes enfants]
}

Frank Weber MD, Hinnerk Wulf MD, Ghada el Saeidi MD

Purpose: To evaluate the efficacy and safety of intranasally administered s-ketamine and midazolam for premedication in pediatric patients.

Methods: Ninety children were randomly allocated to receive intranasally administered s-ketamine $1 \mathrm{mg} \cdot \mathrm{kg}^{-1}$ and midazolam 0.2 $\mathrm{mg} \cdot \mathrm{kg}^{-1}$ (Group KI, $n=30$ ), s-ketamine $2 \mathrm{mg} \cdot \mathrm{kg}^{-1}$ and midazolam $0.2 \mathrm{mg} \cdot \mathrm{kg}^{-1}$ (Group K2, $\mathrm{n}=30$ ), or midazolam $0.2 \mathrm{mg} \cdot \mathrm{kg}^{-1}$ (Group $M, n=30$ ) as premedicants, using a double-blind study design. Sedation and anxiolysis were evaluated using a sedation and cooperation scale and recorded at several time points.

Results: Acceptable conditions (KI : 23; K2: 26, M: 19) for parental separation were not different between groups. Induction conditions were acceptable in 26 patients in $\mathrm{K} 2(P<0.05$ vs $M)(\mathrm{KI}: 23$; $\mathrm{M}$ : 19). Compared to baseline values individual conditions significantly improved in groups $\mathrm{KI}$ and $\mathrm{K} 2$ from 2.5 min after premedication until induction of anesthesia $(P<0.003)$, in group $M$ conditions improved only five minutes after premedication $(P<0.05)$. Adverse effects observed in this series were within an acceptable range and similar for the three groups.

Conclusion: Intranasal administration of s-ketamine and midazolam is an appropriate premedication in preschool children.

Objectif : Évaluer l'efficacité et l'innocuité de l'administration intranasale de s-kétamine et de midazolam comme prémédication chez des patients pédiatriques.

Méthode : L'étude à double insu a porté sur 90 enfants, répartis au hasard, qui ont reçu I mg. $\mathrm{kg}^{-1}$ de s-kétamine et $0,2 \mathrm{mg} \cdot \mathrm{kg}^{-1}$ de midazolam (Groupe KI, n= 30); $2 \mathrm{mg} \cdot \mathrm{kg}^{-1}$ de s-kétamine et 0,2 $\mathrm{mg} \cdot \mathrm{kg}^{-1}$ de midazolam (Groupe K2, $\mathrm{n}=30$ ) ou $0,2 \mathrm{mg} \cdot \mathrm{kg}^{-1}$ de midazolam (Groupe $M, n=30$ ) en prémédication intranasale. La sédation et l'anxiété ont été évaluées selon une échelle de sédation et de coopération et notées à différents moments.

Résultats : La séparation d'avec les parents (KI : 23 ; K2: 26, M : 19) a été acceptable et comparable d'un groupe à l'autre. Les conditions d'induction ont été acceptables chez 26 patients du groupe $K 2$ $(P<0,05$ vs $M)(K I: 23 ; M: 19)$. Comparées aux valeurs de base, les conditions individuelles se sont significativement améliorées chez les enfants des groupes $K 1$ et $K 2$ de 2,5 min après la prémédication jusqu'à l'induction de l'anesthésie $(P<0,003)$. Dans le groupe $M$, les conditions se sont améliorées seulement cinq minutes après la prémédication $(P<0,05)$. Les effets indésirables observées dans cette série sont demeurés à l'intérieur de limites acceptables et ont été comparables entre les groupes.

Conclusion : L'administration intranasale de s-kétamine et de midazolam constitue une prémédication appropriée chez de jeunes enfants.

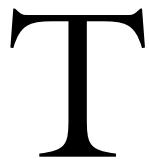

HE preanesthetic management of infants and children can be a challenge for the anesthesiologist. Premedication should provide effective anxiolysis and conscious sedation to improve the conditions for parental separation and induction of general anesthesia.

Midazolam and ketamine have been used as premedicants for infants and children by different routes. The im route is painful and therefore rarely used in pediatric patients. Rectal and oral application of midazolam $^{1,2}$ and ketamine ${ }^{3}$ are widely used in this age group. With an onset time between 15 and $30 \mathrm{~min}^{3-5}$

From the Clinic for Anesthesiology and Critical Care Medicine, University Hospital Kiel, Kiel, Germany.

Address correspondence to: Dr. Frank Weber, Department of Anesthesia, University of Regensburg, 93042 Regensburg, Germany.

Phone: +49 941 944-7827; Fax: +49 941 944-7802; E-mail: frank.weber@klinik.uni-regensburg.de

Disclosure statement: this study was supported by Parke Davis Ltd., Germany.

The results of this study were presented, in part, at the German Congress of Anesthesiology, Wiesbaden, Germany, 2-6 May 1999. Accepted for publication November 20, 2002.

Revision accepted February 12, 2003. 
they show a rather slow onset of sedation, and first pass hepatic metabolism results in a low and unpredictable systemic availability. ${ }^{6,7}$ Furthermore both rectal and oral routes can be used successfully only in children who generally accept premedication, otherwise either spitting out (oral route) or immediate defecation (rectal route) may result.

Intranasal midazolam for premedication in preschool children was first described and advocated by Wilton and colleagues. ${ }^{8}$ Racemic ketamine as a premedicant has been successfully administered via the nasal route ${ }^{9,10}$ as well. Combinations of midazolam and ketamine given orally ${ }^{11,12}$ or rectally ${ }^{4}$ have been shown to result in better premedication than either drug alone.

Audenaert and colleagues ${ }^{13}$ investigated the cardiac effects of different pediatric premedication regimes and recommended the combination of intranasally administered ketamine $5 \mathrm{mg} \cdot \mathrm{kg}^{-1}$ and midazolam 0.2 $\mathrm{mg} \cdot \mathrm{kg}^{-1}$ especially in children with tenuous cardiocirculatory status. Data concerning the sedative effects of this concept have not been published.

$S$-ketamine, one of the two ketamine isomers is now available in Germany. S-ketamine has twice the anesthetic potency of racemic ketamine. ${ }^{14}$ Thus, a 50\% reduction of dosage is possible to achieve comparable results. Because of faster elimination of s-ketamine, better control of anesthesia will be provided..$^{15}$ Furthermore it produces less psychomimetic side effects than racemic ketamine ${ }^{16}$ because these are mainly caused by r-ketamine ${ }^{17}$ the other enantiomer of racemic ketamine.

Considering the effects of intranasally administered s-ketamine and midazolam for pediatric premedication remain unclear, we conducted a prospective randomized double-blind clinical trial. The purpose of this study was to evaluate the efficacy and safety of three different regimes for pediatric premedication. We compared the sedative and anxiolytic effects of two different doses of intranasally administered s-ketamine ( 1 or $2 \mathrm{mg} \cdot \mathrm{kg}^{-1}$ ) combined with midazolam 0.2 $\mathrm{mg} \cdot \mathrm{kg}^{-1}$ and midazolam $0.2 \mathrm{mg} \cdot \mathrm{kg}^{-1}$ alone.

\section{Patients and methods}

After obtaining Ethical Committee approval and written parental consent, we studied 90 healthy infants and children (ASA I/II), aged six months to six years, presenting for elective minor surgery under general anesthesia. Children were randomized by a computer-generated assignment to receive via the nasal route, in a doubleblind manner, either midazolam $0.2 \mathrm{mg} \cdot \mathrm{kg}^{-1}$ and s-ketamine $1 \mathrm{mg} \cdot \mathrm{kg}^{-1}\left(0.08 \mathrm{~mL} \cdot \mathrm{kg}^{-1}\right)$ [Group $\mathrm{Kl}$ ], midazolam $0.2 \mathrm{mg} \cdot \mathrm{kg}^{-1}$ and s-ketamine $2 \mathrm{mg} \cdot \mathrm{kg}^{-1}(0.12$ $\mathrm{mL} \cdot \mathrm{kg}^{-1}$ ) [Group K2] or, as a control group, midazolam $0.2 \mathrm{mg} \cdot \mathrm{kg}^{-1}$ (1:1 in normal saline, $0.08 \mathrm{~mL} \cdot \mathrm{kg}^{-1}$ ) [Group M]. The maximum dose for midazolam was 5 $\mathrm{mg}$ for all three groups. Maximum s-ketamine doses were $25 \mathrm{mg}(\mathrm{Kl})$ and $50 \mathrm{mg}(\mathrm{K} 2)$.

Premedication was given to the children on the ward by a nurse or the parents, using a syringe of appropriate size $(1 / 2 / 5 \mathrm{~mL})$ without a needle. The whole volume was given into one nostril while the child was either sitting on the parent's lap or on the bed. During the whole study period oxygen saturation and heart rate were continuously monitored using a portable pulse oximeter (Oxycount ${ }^{\circledR}$ mini, Andos, Karlsruhe, Germany). After inhalational induction of anesthesia with sevoflurane $8 \%$ and $\mathrm{N}_{2} \mathrm{O}$ in $50 \% \mathrm{O}_{2}$, the airway was secured by endotracheal intubation or placement of a laryngeal mask. The children were then mechanically ventilated to normocapnia with $\mathrm{N}_{2} \mathrm{O}$ in $30 \% \mathrm{O}_{2}$ and sevoflurane as necessary. Intraoperatively no additional opioids or $i$ sedatives were given. At the end of surgery sevoflurane delivery was discontinued and mechanical ventilation was continued with $100 \%$ oxygen. All patients were extubated awake. Postoperative analgesia was provided by either rectal paracetamol $20 \mathrm{mg} \cdot \mathrm{kg}^{-1}$ or regional anesthesia as appropriate.

TABLE I Sedation score (adapted from Wilton and colleagues) ${ }^{8}$

\begin{tabular}{llll}
\hline Sedation level & Child untouched & Additional assessment of cooperation \\
\hline 1 (Agitated) & $\begin{array}{l}\text { Clinging to parent and /or crying } \\
\text { Awake but not clinging to parents, may whimper } \\
\text { but not cry loudly }\end{array}$ & $\begin{array}{l}\text { Criteria score } 1 \text { and / or vigorous refusal } \\
\text { Criteria score } 1 \text { and / or initial refusal; but } \\
\text { accepts with persuasion } \\
\text { Criteria score } 1 \text { and helps to perform the manipulation }\end{array}$ \\
3 (Alert) & $\begin{array}{l}\text { Sitting or lying comfortably with eyes } \\
\text { spontaneously open }\end{array}$ & $\begin{array}{l}\text { Lying comfortably with eyes spontaneously closing, } \\
\text { responds to minor stimulation }\end{array}$ & Criteria score 1 and accepts the manipulation \\
4 (Drowsy) & Eyes closed, rousable but does not respond to & Criteria score 1 and accepts the manipulation \\
\hline
\end{tabular}

Sedation and anxiolysis were evaluated in untouched patients. For additional evaluation of cooperation (placement of the pulse oximetry sensor, electrocardiogram electrodes and mask induction of anesthesia) the score was modified. 
Sedation was estimated by a single observer according to a sedation scale adapted from Wilton and colleagues, ${ }^{8}$ who performed a composite evaluation based on sedation, anxiolysis and cooperation, leading to the determination of a "sedation level" scored 1 to 5 (Table I). Sedation was assessed in "untouched children" 2.5 and five minutes after drug administration, immediately after separation from the parents (ten minutes after drug administration) and immediately after the arrival in the postanesthetic care unit (PACU). As did Wilton and colleagues, we modified the scoring-system to assess the acceptance of direct manipulations. Sedation, anxiolysis and cooperation were recorded immediately before intranasal drug administration (baseline value), during placement of the anesthesia monitoring devices (electrocardiogram, pulse oximetry) and during mask induction of general anesthesia.

For statistical analysis the sedation scale values were condensed to a variable consisting of three categories: unacceptable conditions (levels 1 and 2), acceptable conditions (levels 3 and 4 ) and unacceptable deep sedation (level 5).

Patients with a time interval longer than $120 \mathrm{~min}$ between premedication and the end of anesthesia were excluded from postoperative assessment of the sedation scores.

Heart rate was monitored by continuous pulse oximetry throughout the study period to detect possible cardiovascular effects of premedication. We did not measure blood pressure because this procedure often causes discomfort, which might lead to interference with the assessment of anxiolysis and sedation.

Immediate reactions to premedication were recorded. Adverse effects, if any, especially odd behaviour or unexplained distress and excessive salivation, were recorded.

\section{Sample size determination and statistical analysis}

Our study was designed to detect an increase in the rate of acceptable conditions (sedation scale levels 3 and 4 ) for separation and induction from $76 \%$ to $95 \%$ with a power of $80 \%$ and an alpha error of less than $5 \%$. The $76 \%$ success rate was taken from a study by Wilton and colleagues ${ }^{8}$ who used intranasally administered midazolam $0.2 \mathrm{mg} \cdot \mathrm{kg}^{-1}$. Power analysis was performed using software [Faul, F. Erdfelder, E. (1992) GPower: A priori, post-hoc, and compromise power analyses for MS-DOS (Computer Program). Bonn, FRG: Bonn University, Dept of Psychology]. Sample size was estimated at 29 patients in each group. To compensate for possible dropouts we chose a sample size of 30 patients in each group. Statistical analysis was undertaken using a statistical software package
TABLE II Patient data and distribution of operative procedures

\begin{tabular}{llll}
\hline Group & $K 1$ & $K 2$ & $M$ \\
\hline$n$ & 30 & 30 & 30 \\
Age (yr) & $4.7(1.4)$ & $4.6(1.7)$ & $4.2(1.7)$ \\
Weight (kg) & $18.2(4.3)$ & $18.0(4.8)$ & $16.7(4.3)$ \\
Duration of anesthesia (min) & $59(13)$ & $57(15)$ & $50(12)$ \\
female / male ratio & $16 / 14$ & $13 / 17$ & $13 / 17$ \\
Operative procedures & & & \\
Strabismus correction & 20 & 23 & 24 \\
Inguinal hernia repair & 4 & 3 & 2 \\
Dental repair & 2 & 2 & 3 \\
Adenoidectomy & 2 & 1 & 1 \\
Circumcision & 2 & 1 & 0 \\
\hline
\end{tabular}

Data are means (SD). There are no significant intergroup differences.

TABLE III Individual changes of sedation levels at different observation times compared to baseline values

\begin{tabular}{llll}
\hline & $\begin{array}{c}\text { Acceptable to } \\
\text { unacceptable }\end{array}$ & $\begin{array}{c}\text { Unacceptable } \\
\text { to acceptable }\end{array}$ & $\begin{array}{l}\text { Significance } \\
\text { level }\end{array}$ \\
\hline Group K1 & & & \\
2.5 min & 2 & 11 & $P=0.012$ \\
5 min & 1 & 16 & $P<0.0001$ \\
Separation & 1 & 18 & $P<0.0001$ \\
Monitoring & 1 & 16 & $P<0.0001$ \\
Induction & 1 & 16 & $P<0.0001$ \\
PACU & 8 & 7 & n. s. \\
Group K2 & & & \\
2.5 min & 1 & 15 & $P<0.0001$ \\
5 min & 0 & 19 & $P<0.0001$ \\
Separation & 0 & 18 & $P<0.0001$ \\
Monitoring & 0 & 19 & $P<0.0001$ \\
Induction & 0 & 17 & $P<0.0001$ \\
PACU & 3 & 8 & n. s. \\
Group $M$ & & & \\
2.5 min & 2 & 8 & n. s. \\
5 min & 1 & 11 & $P=0.003$ \\
Separation & 3 & 10 & n. s. \\
Monitoring & 3 & 10 & n. s. \\
Induction & 4 & 10 & n. s. \\
PACU & 7 & 5 & n. s. \\
\hline
\end{tabular}

$\mathrm{PACU}=$ postanesthesia care unit; $\mathrm{n} . \mathrm{s} .=$ non significant.

(StatView, version 4.5, Abacus Concepts, Inc., Berkeley, CA, USA). The Chi-square test was used for comparison of intergroup differences of the sedation score levels. Continuous data were compared using the Kruskal-Wallis method and the Wilcoxon signed rank test as appropriate. The McNemar test [Uitenbroek, Daan G. Binomial. SISA. 1997; http://home.clara.net/sisa/binomial.htm. (1 Jan. 2001)] was performed to assess individual changes of the sedation score levels. 


\section{Results}

Ninety children were studied in the three groups $(\mathrm{Kl}$ : $30 ; \mathrm{K} 2: 30 ; \mathrm{M}: 30$ ). The groups were comparable with respect to age, weight gender and distribution of operative procedures (Table II). Ten patients (Kl: 5; K2: 1; M: 4) were excluded from postoperative evaluation, because their premedication-extubation time interval exceeded $120 \mathrm{~min}$.

Intragroup comparison of changes in sedation scores of individual patients at different times against baseline values showed significantly improved sedation conditions in groups $\mathrm{Kl}$ and $\mathrm{K} 2$ from 2.5 min after premedication until induction of general anesthesia, whereas in group $M$ conditions improved only five minutes after premedication (Table III).

Intergroup comparison $v s$ group $M$ did not reveal better sedation conditions for group $\mathrm{Kl}$ at any time. Patients in group K2 presented with significantly better conditions from five minutes after premedication until induction except for separation from the parents (Figure 1).

Ten patients in group $\mathrm{K} 2$ had a sedation level of 1 immediately before premedication ( $\mathrm{Kl}: 3, \mathrm{M}: 5)$. During induction of general anesthesia there were no patients in group $\mathrm{K} 2$ presenting with a sedation level of 1 ( $\mathrm{Kl}: 4, \mathrm{M}: 7)$.

Changes in heart rate, compared to baseline values showed significantly higher values at induction and after arrival in the recovery room for groups $\mathrm{Kl}$ and $\mathrm{M}$. In group $\mathrm{K} 2$ heart rates were significantly lower five minutes after premedication and during separation from the parents (Figure 2). Mean heart rates were lower than baseline values in group $\mathrm{K} 2$ throughout the study period.

Oxygen saturation was $\geq 96 \%$ throughout the whole observation period in all children.

\section{Side effects}

Immediately after drug administration all patients complained either verbally (bitter taste) or non-verbally (infants and toddlers). These complaints lasted less than $2.5 \mathrm{~min}$ in all patients. None of the 90 children reached a sedation level of 5 , which represents deep sedation. Excessive salivation did not occur.

\section{Discussion}

In our study midazolam $0.2 \mathrm{mg} \cdot \mathrm{kg}^{-1}$ [Group M] led to good conditions for separation and induction in $73 \%$ and $63 \%$ of patients respectively. Wilton and colleagues ${ }^{8}$ administered midazolam $0.2 \mathrm{mg} \cdot \mathrm{kg}^{-1}$ nasally for premedication in preschool children. Defining sedation levels higher than 1 (agitated) as successful premedication they achieved good conditions for

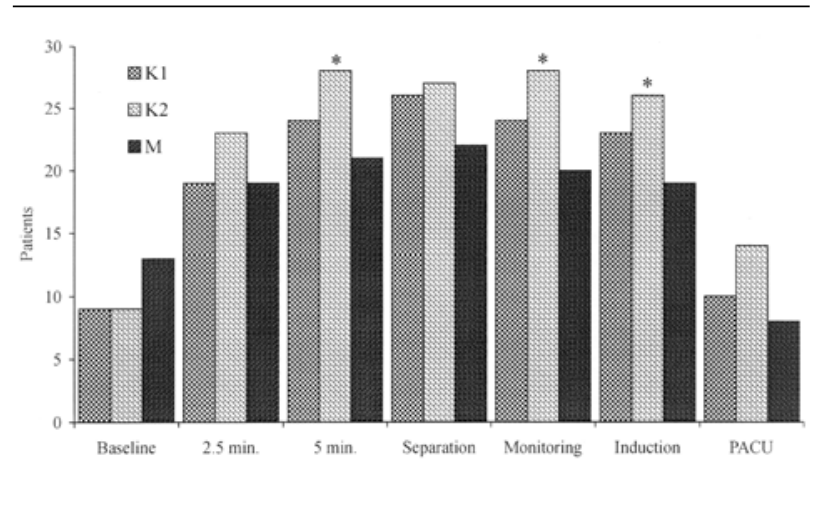

FIGURE 1 Patients with acceptable sedation levels at different observation times ( ${ }^{*}<0.05$ intergroup difference $v$ s Group $\left.M\right)$.

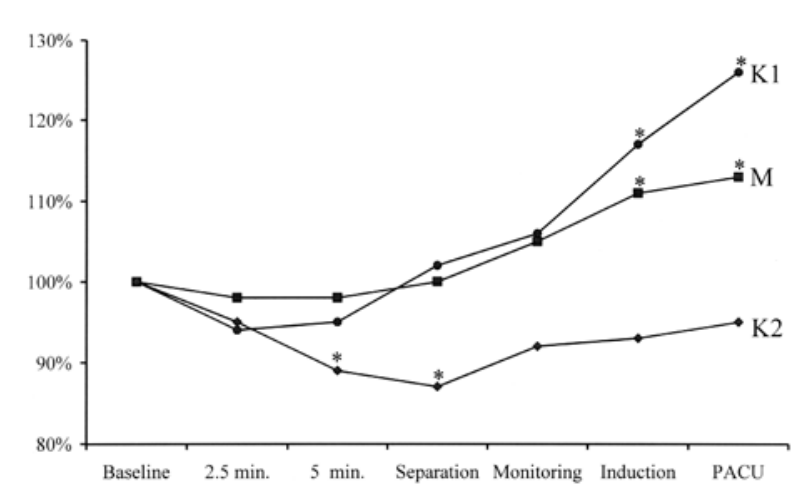

FIGURE 2 Changes of mean heart rate, in percent compared to baseline value $(100 \%)$ immediately before premedication $\left({ }^{*} P<\right.$ 0.05 intragroup difference $v s$ baseline values).

parental separation and inhalational induction of general anesthesia in $93 \%$ of their patients. Applying our criteria for successful premedication (sedation levels 3 and 4) to their data leads to success rates of $73 \%$ for separation and $80 \%$ for induction.

The combination of midazolam $0.2 \mathrm{mg} \cdot \mathrm{kg}^{-1}$ and sketamine $1 \mathrm{mg} \cdot \mathrm{kg}^{-1}(\mathrm{Kl})$ did not significantly improve sedation and cooperation conditions when compared to group M. Conditions in group K2 were significantly better compared to group $\mathrm{M}$ from five minutes after premedication until induction except for parental separation. Individual sedation scores improved significantly in groups $\mathrm{Kl}$ and $\mathrm{K} 2$ from $2.5 \mathrm{~min}$ after premedication until induction of general anesthesia.

Only in group K2 was there no child presenting with a sedation level of 1 during induction of general 
anesthesia (Kl: 4, M: 7). On the other hand, ten children were scored level 1 in group K2 immediately before premedication ( $\mathrm{Kl}: 3, \mathrm{M}: 5)$. Due to the predetermined classification of the sedation scores $(1$ and 2: unacceptable, 3 and 4: acceptable, 5: unacceptable deep sedation) this was not taken into account for statistical analysis, but might suggest the superiority of the $\mathrm{K} 2$ combination compared to groups $\mathrm{Kl}$ and $\mathrm{M}$.

The evolution of individual sedation levels during the study period (Table III) shows a tendency from acceptable conditions before premedication (baseline) to unacceptable conditions for parental separation and induction in groups $\mathrm{M}$ and $\mathrm{Kl}$. Only in group K2 were conditions for parental separation and induction identical or better compared to baseline values in all 30 children studied. In our opinion it is more important to assess the evolution of the behavioural status under different degrees of emotional stress (baseline separation - induction) than to look at overall numbers of sedation levels irrespective of the individual evolution of sedation or agitation.

The evolution of heart rate after premedication (Figure 2) indicates that nasally applied s-ketamine 2 $\mathrm{mg} \cdot \mathrm{kg}^{-1}$ does not induce clinically detectable sympathomimetic effects. In contrast to groups $\mathrm{M}$ and $\mathrm{Kl}$, in group $\mathrm{K} 2$ mean heart rate was lower throughout the entire study period compared to baseline values $(P$ $<0.05$, five minutes after premedication and after separation from the parents). In groups $\mathrm{M}$ and $\mathrm{Kl}$ there was a significant rise in mean heart rate during induction and after arrival in the PACU. These findings parallel the larger number of children with unacceptable sedation scores during induction and after arrival in the PACU in groups $\mathrm{M}$ and $\mathrm{Kl}$.

Our study supports the data presented by Audenaert and colleagues ${ }^{13}$ who found that the combination of intranasally administered racemic ketamine $5 \mathrm{mg} \cdot \mathrm{kg}^{-1}$ and midazolam $0.2 \mathrm{mg} \cdot \mathrm{kg}^{-1}$ did not produce significant cardiovascular and respiratory side effects. Taking into account that racemic ketamine has approximately half the potency of s-ketamine, ${ }^{14}$ this dosage is comparable to our group K2.

Louon and Reddy ${ }^{18}$ used a mixture of ketamine 5 $\mathrm{mg} \cdot \mathrm{kg}^{-1}$ and midazolam $0.56 \mathrm{mg} \cdot \mathrm{kg}^{-1}$ given intranasally to induce deep sedation for computerized tomography. As intended by the investigators, two thirds of the patients fell asleep with stable vital signs within five to $20 \mathrm{~min}$ after drug administration. The aim of our study was not to obtain deep sedation but to produce calm, fully awake and cooperative children. In our study no child presented deep sedation.

Sample size for this study was calculated to examine efficacy, not safety. Thus, we can only state that, based on this limited study, no serious complications were encountered. This and previously published studies on nasal ketamine and midazolam in children ${ }^{8-10,13,18}$ without any reports of serious complications are no formal safety proof. One theoretical serious complication would be the penetration of s-ketamine and midazolam through the cribriform plate, giving rise to high central nervous system levels. However, serious complications are likely very rare and a very large study size would be required to demonstrate safety conclusively. Because of the very rapid onset of sedation we recommend the use of a pulse oximeter and continuous observation of the child after nasal premedication.

All 90 patients complained of the bitter taste of the premedication, but these complaints were very shortlived, lasting less than $2.5 \mathrm{~min}$ after premedication. We did not observe any other adverse effect.

A possible criticism of our study might be that we used volumes of $0.8-1.2 \mathrm{~mL} \cdot \mathrm{kg}^{-1}$ for intranasal drug administration. Apart from drug absorption over the nasal mucosa, significant parts of the medication will go to the pharynx where absorption via the pharyngeal mucosa occurs and the remaining volume will be swallowed. Thus we must emphasize that the term nasal premedication describes the mode of drug administration and not necessarily the single route of drug absorption.

In conclusion, nasal administration of s-ketamine and midazolam to preschool children provides good conditions for induction of anesthesia; furthermore it shows a very rapid onset of action without evidence of serious adverse effects. This premedication regime may be an alternative to any of those that have been reported over the last two decades in children where a rapid onset of anxiolysis and sedation is desired.

\section{Acknowledgement}

The authors gratefully acknowledge Parke Davis Ltd, Germany for providing financial support.

\section{References}

1 Spear RM, Yaster M, Berkowitz ID. Preinduction of anesthesia in children with rectally administered midazolam. Anesthesiology 1991; 74: 670-4.

2 Feld LH, Negus JB, White PF. Oral midazolam preanesthetic medication in pediatric outpatients.

Anesthesiology 1990; 73: 831-4.

3 Gutstein HB, Johnson KL, Heard MB, Gregory GA. Oral ketamine preanesthetic medication in children. Anesthesiology 1992; 76: 28-33.

4 Warner DL, Cabaret J, Velling D. Ketamine plus midazolam, a most effective paediatric oral premedicant. Paediatr Anaesth 1995; 5: 293-5. 
5 Sekerci S, Dönmez A, Ates $\Upsilon$, Ökten F. Oral ketamine premedication in children (placebo controlled doubleblind study). Eur J Anaesthesiol 1996; 13: 606-11.

6 Malinovsky JM, Lejus C, Servin F, et al. Plasma concentrations of midazolam after i.v., nasal or rectal administration in children. Br J Anaesth 1993; 70: 617-20.

7 Malinovsky JM, Servin F, Cozian A, Lepage JY, Pinand $M$. Ketamine and norketamine plasma concentrations after i.v., nasal and rectal administration in children. $\mathrm{Br}$ J Anaesth 1996; 77: 203-7.

8 Wilton NCT, Leigh J, Rosen DR, Pandit UA. Preanesthetic sedation of preschool children using intranasal midazolam. Anesthesiology 1988; 69: 972-5.

9 Weksler N, Ovadia L, Muati G, Stav A. Nasal ketamine for paediatric premedication. Can J Anaesth 1993; 40: 119-21.

$10 \mathrm{Diaz} J \mathrm{H}$. Intranasal ketamine preinduction of paediatric outpatients. Paediatr Anaesth 1997; 7: 273-8.

11 Funk W, Jakob W, Riedl T, Taeger K. Oral preanaesthetic medication for children: double-blind randomized study of a combination of midazolam and ketamine vs midazolam or ketamine alone. $\mathrm{Br} \mathrm{J}$ Anaesth 2000; 84: 335-40.

12 Lökken P, Bakstad OJ, Fonnelop E, et al. Conscious sedation by rectal administration of midazolam or midazolam plus ketamine as alternatives to general anesthesia for dental treatment of uncooperative children. Scand J Dent Res 1994; 102: 274-80.

13 Audenaert SM, Wagner $\Upsilon$, Montgomery CL, et al. Cardiorespiratory effects of premedication for children. Anesth Analg 1995; 80: 506-10.

14 Hempelmann G, Kubn DF. Clinical significance of S(+)-Ketamine (German). Anaesthesist 1997; 46(Suppl 1): $S 3-7$.

15 Adams HA, Werner C. From the racemate to the eutomer: (S)-ketamine. Renaissance of a substance? (German). Anaesthesist 1997; 46: 1026-42.

16 Doenicke A, Kugler J, Mayer M, Angster R, Hoffmann $P$. Ketamine racemate or S-(+)-ketamine and midazolam. The effect on vigilance, efficacy and subjective findings (German). Anaesthesist 1992; 41: 610-8.

17 Kress $H G$. Mechanisms of action of ketamine (German). Anaesthesist 1997; 46(Suppl 1): S8-19.

18 Louon A, Reddy VG. Nasal midazolam and ketamine for paediatric sedation during computerised tomography. Acta Anaesthesiol Scand 1994; 38: 259-61. 